\title{
Pembuatan dan Pengujian Panel Honeycomb Sandwich dengan Inti Berbentuk Gelombang Berbahan Komposit Serat Bambu
}

\author{
Marsono, Sarah Fauziyyah Hanifa, Faizal Akbar \\ Teknik Mesin, Fakultas Teknik Industri, Institut Teknologi Nasional Bandung, Indonesia \\ Email:marsono@itenas.ac.id
}

Received 2 Februari 2021 | Revised 15 Juli 2021 | Accepted 22 Juli 2021

\begin{abstract}
ABSTRAK
Dalam penelitian ini, komposit serat bambu dibuat menjadi panel struktur honeycomb sandwich dan diuji untuk mengukur kemungkinan pemanfaatannya sebagai bahan untuk membuat sudu turbin angin sumbu vertical. Honeycomb sanwich serat bambu yang dibuat memiliki inti (core) yang berbentuk gelombang sinus pada arah memanjang panel. Sebagai pengikat pada komposit ini digunakan resin polyester. Panel honeycomb sandwich yang dibuat memiliki panjang $500 \mathrm{~mm}$ dan lebar 200mm, sedangkan tebal panel dibuat dengan dua variasi, yaitu dengan tinggi inti honeycomb $12 \mathrm{~mm}$ dan $17 \mathrm{~mm}$. Panel honeycomb sandwich ini diuji dengan uji bending untuk mendapatkan angka kekuatan lentur (flexural strength) dan angka kekakuan (stiffness). Dari tiga panel yang dibuat identik untuk masih-masing ketinggian inti honeycomb, diperoleh angka kekuatan lentur dan kekakuan terbesar pada panel dengan ketinggian inti honeycomb17mm, yaitu dengan angka kekuatan lentur $0,91 \mathrm{~kg} / \mathrm{mm}^{2}$ dan angka kekakuan $11,35 \mathrm{~kg} / \mathrm{mm}$
\end{abstract}

Kata kunci: honeycomb sandwich, komposit serat bambu,gelombang sinus, kekuatan lentur, kekakuan.

\begin{abstract}
In this research, bamboo fiber composite are made into honeycomb sandwich structure panel and to be tested for its ability as a material for vertical axis wind turbine blades. Bamboo fiber honeycomb sandwich had a sinusoidal-shaped core in the longitudinal direction of the panel. Polyester resin was used as a binder on this composite. The honeycomb panels that have been made have a length of $500 \mathrm{~mm}$ and a width of $200 \mathrm{~mm}$. The thickness of the panels was made of two variations, which was has $12 \mathrm{~mm}$ and $17 \mathrm{~mm}$ honeycomb core-height. The honeycomb sandwich panel was tested by bending test to obtain flexural strength and stiffness. From the three panels that have been made in identical dimension for each honeycomb coreheight, the highest flexural strength and stiffness was obtained in the specimen with the honeycomb coreheight of $17 \mathrm{~mm}$, with a flexural strength of $0,91 \mathrm{~kg} / \mathrm{mm}^{2}$ and astiffness of $11,35 \mathrm{~kg} / \mathrm{mm}$.
\end{abstract}

Keywords: honeycomb sandwich, bamboo fiber composite, sinusoidal wave, flexurall strength, stiffness. 


\section{PENDAHULUAN}

Angin adalah sumber daya yang sangat mudah untuk didapatkan dengan biaya yang murah dan tidak akan pernah habis. Pemanfaatan energi angin yang dikonversikan menjadi energi listrik dengan memamfaatkan turbin angin akan menjadi salah satu solusi dari permasalahan krisis energi saat ini. Pemanfaatan energi angin sebagai sumber energi alternatif akan sangat membantu mengurangi ketergantungan terhadap sumber energi fosil dan tentunya akan membantu mengurangi emisi karbondioksida, karbonmonoksida serta pencemar udara lainnya sebagai produk dari pembakaran bahan bakar fosil yang tidak sempurna yang akan berdampak terhadap perubahan iklim global [1].

Salah satu tantangan besar dari pengembangan turbin angin adalah pemanfaatan material alternatif untuk mendapatkan sudu yang memiliki kekuatan dan kekakuan yang cukup tinggi namun memiliki bobot yang ringan. Kekakuan sudu yang rendah akan berdampak terhadap perubahan bentuk dan dimensi sudu. Hal ini akan mengakibatkan penurunan kinerja turbin angin. Salah satu inovasi yang telah dikembangkan di beberapa negara seperti Jepang dan China terkait dengan material untuk membuat sudu turbin angin adalah pemanfaatan serat bambu sebagai alternatif dari penggunaan serat kaca dan serat karbon [2].

Bambu adalah salah satu alternatif bahan baku serat alami lignoselulosa yang memiliki potensi paling besar karena tanaman in paling cepat tumbuh. Bambu banyak ditemukan di daerah tropis dan sub-tropis [3]. Dengan ketersediaan yang melimpah, bambu memiliki kelebihan dalam hal harganya yang murah. Bambu juga memiliki sifat ramah lingkungan karena mudah terurai serta tidak memiliki dampak buruk terhadap kesehatan manusia [4]. Bambu yang merupakan serat alami memiliki sifat dapat diperbaharui (renewable) serta memiliki sustainabilitas yang lebih baik dibandingkan serat sintetik seperti serta kaca dan serat karbon [5].

Aplikasi serat bambu pada komposit berpenguat serat (FRC $=$ Fiber Reinforce Composite) memberikan dampak yang signifikan karena memiliki kekuatan dan kekakuan yang tinggi. Dibandingkan dengan serat alami yang lain, serat bambu memiliki ketangguhan dan kekuatan yang lebih tinggi, densitas yang rendah serta kekuatan spesifik (specific strength) yang cukup baik. Hal ini membuat bambu setara dengan serat kaca dalam hal kekuatan spesifiknya. Jika dibandingkan dengan baja lunak, kekuatan spesifik dari bambu bisa mencapai 3 sampai 4 kali dari kekuatan spesifik baja lunak [5].

Pengembangan material dengan struktur sandwich bertujuan untuk mendapatkan material dengan bobot yang ringan (light weight) dengan kekuatan (strength) dan kekakuan (stiffness) yang tinggi. Material dengan struktur sandwich akan memiliki kekuatan spesifik (rasio kekuatan persatuan berat) yang lebih tinggi daripada material dalam bentuk padat (pejal). Bahan polimer berpenguat serat (FRP $=$ Fiber Reinforce Polymer) telah digunakan untuk membuat material dengan struktur sandwich sejak akhir abad 20, dimana sebelumnya material dengan struktur sandwich dibuat hanya dengan bahan logam. Penggunaan FRP akan membuat material dengan struktur sandwich menjadi semakin ringan jika dibandingkan penggunaan bahan logam. Material FRP juga mudah dibentuk untuk mendapatkan geometri yang kompleks [6].

Material dengan struktur sandwich secara umum memiliki tiga bagian utama, yaitu satu bagian inti (core) dan dua bagian kulit (face/skin). Bagian kulit yang terletak dibagian luar dibuat dengan material yang relatif tipis, kaku dan kuat. Kedua kulit dipisahkan oleh material inti yang tebal. Material inti struktur sandwich umumnya memiliki bentuk berongga yang berupa bentuk sarang lebah (honeycomb), bentuk sel (cellular) ataupun busa (foam) [7], [8]. Inti dengan bentuk bergelombang (corrugated core) mulai dikenal sejak awal abad 20 dengan beberapa variasi bentuk. Bentuk inti gelombang yang paling sering digunakan adalah bentuk sinusoidal dan trapezoidal [6]. Struktur sandwich dengan inti berbentuk gelombang memiliki kelebihan untuk menahan beban tekan dan beban geser. Inti berbentuk gelombang memiliki kekuatan 3 sampai 7 kali lebih tinggi dibandingkan dengan inti berbentuk selular [9]. 
Sampai saat ini, belum banyak penelitian tentang pemanfaatan serat bambu yang panjang untuk pembuatan komposit berpenguat serat bambu (BFRC = Bamboo Fiber Reinforce Composite) maupun untuk pembuatan material dengan stuktur sandwich berbahan BFRC. Penelitian tentang material dengan struktur sandwich dan honeycomb sandwich dengan bahan komposit serat bambu lebih banyak menggunakan bahan baku serat bambu berupa serat-serat pendek, serbuk (particle) dan stick bambu, seperti yang dilakukan antara lain oleh Yang, et. al.[9], Roslan, et. al [10] dan Hassan, et. al.[11]. Pada tingkat industri, BFRC lebih banyak dibuat dengan bahan baku bambu berupa serat-serat pendek dan serbuk bambu karena penanganannya lebih mudah.

Penelitian ini bertujuan terutama untuk mengetahui sifat mekanik dari komposit berpenguat serat bambu dalam bentuk material dengan struktur honeycombsandwich. Bagian inti dan bagian kulit dari struktur honeycomb sandwich dalam penelitian ini dibuat dengan menggunakan serat bambu yang panjang, berbeda dengan umumnya penelitian yang telah dilakukan sampai saat ini. Material dengan struktur honeycombsandwich berbahan komposit serat bambu ini diharapkan nantinya dapat dimanfaatkan dalam pembuatan sudu turbin Savonius. Inti (core) dari struktur honeycomb sandwich yang dibuat memiliki bentuk gelombang sinus. Material dengan stuktur honeycomb sandwich yang dibuat masih berupa spesimen panel papan segiempat, belum dalam bentuk sudu turbin Savonius yang berbentuk profil setengah lingkaran. Di sisi lain, penelitian ini juga bertujuan untuk menemukan metoda yang sederhana dan mudah diterapkan untuk membuat honeycomb sandwich dengan inti berbentuk gelombang sinus dari bahan komposit serat bambu. Hal ini penting untuk dilakukan mengingat belum banyak yang mengembangkan komposit bermatriks polimer dengan penguat serat bambu yang panjang dalam bentuk material dengan struktur honeycomb sandwich. Penelitianini pun masih berada pada tahap awal dalam skala percobaan laboratorium, belum sampai pada tingkat produksi dalam skala industri.

\section{METODOLOGI}

\subsection{Pemanfaatan honeycomb sandwich untuk sudu turbin angin}

Indonesia adalah negara kepulauan yang memiliki garis pantai yang sangat panjang. Daerah pantai memiliki potensi sumber daya angin yang cukup besar dan dapat dimanfaatkan sebagai penggerak turbin angin. Dengan kondisi geografis seperti ini, Indonesia tentu saja memiliki kesempatan yang sangat besar untuk mengurangi ketergantungan terhadap energi fosil sebagai sumber energi untuk instalasi pembangkit listrik dan menggantikannya dengan energi angin.

Rancangan sebuah turbin angin harus disesuaikan dengan kondisi dan potensi sumber daya angin yang tersedia di suatu tempat. Hal ini bertujuan agar diperoleh efisiensi energi yang maksimal dari pemanfaatan turbin angin. Dengan kecepatan rata-rata angin di perairan Indonesiayang relatif rendah, yaitu berada di kisaran $4 \mathrm{~m} / \mathrm{s}-5 \mathrm{~m} / \mathrm{s}[12]$, maka turbin angin yang cocok untuk digunakan di Indonesia adalah turbin angin jenis Savonius yang memiliki sumbu putar vertikal.

Rancangan sebuah turbin harus kuat menahan beban akibat dorongan angin (drag force) dalam arti beban tersebut tidak mengubah bentuk dan dimensi sudu turbin secara berlebihan. Perubahan bentuk dan dimensi yang berlebihan pada sudu turbin angin akan menurunkan kinerja turbin angin tersebut. Salah satu upaya untuk mencegah terjadinya perubahan bentuk dan dimensi sudu akibat gaya dorong angin adalah dengan meningkatkan kekuatan dan kekakuan sudu turbin. Sudu turbin angin juga harus ringan agar dapat mereduksi kehilangan energi akibat melawan gaya inersia yang timbul karena faktor berat sudu [13].

Kekuatan dan kekakuan dari sebuah struktur dapat ditingkatkan dengan cara memperbesar momen inersia penampang. Cara yang paling umum dilakukan untuk mendapatkan momen inersia penampang yang besar adalah dengan cara menambah luas penampang dari suatu batang, namun cara ini akan berdampak kepada penambahan berat. Peningkatan momen inersia penampang tanpa efek penambangan berat yang signifikan pada suatu batang adalah ide dasar pengembangan struktur honeycomb sandwich. Tujuan pengembangan material dengan struktur honeycomb sandwich ini sejalan dengan kebutuhan 
material yang diperlukan untuk sudu turbin angin, yaitu material yang kuat dan kaku namun tetap ringan. Penggunaan serat bambu sebagai penguat (reinforced agent) dalam pengembangan komposit bermatriks polimer sangat cocok dikembangkan di Indonesia karena ketersediaan bambu di Indonesia sangat melimpah. Data survai Biro Pusat Statistik Jakarta tahun 2004 mencatat jumlah tanaman bambu sebanyak 29,14 juta rumpun $(76,83 \%)$ di pulau Jawa dan 8,79 juta rumpun $(23,17 \%)$ di luar pulau Jawa [14].

\subsection{Rancangan panel honeycomb sandwich berbahan komposit serat bambu}

Dalam penelitian ini, honeycomb sandwich yang dibuat memiliki inti yang berbentuk gelombang sinus. Satuan lembaran yang berbentuk gelombang sinus ini disusun berjajar ke arah samping (arah lebar panel). Satuan lembaran gelombang yang berbentuk gelombang sinus ini memiliki perbedaan setengah gelombang dengan lembaran gelombang yang ada disampingnya, sebagaimana yang terlihat pada gambar 1.

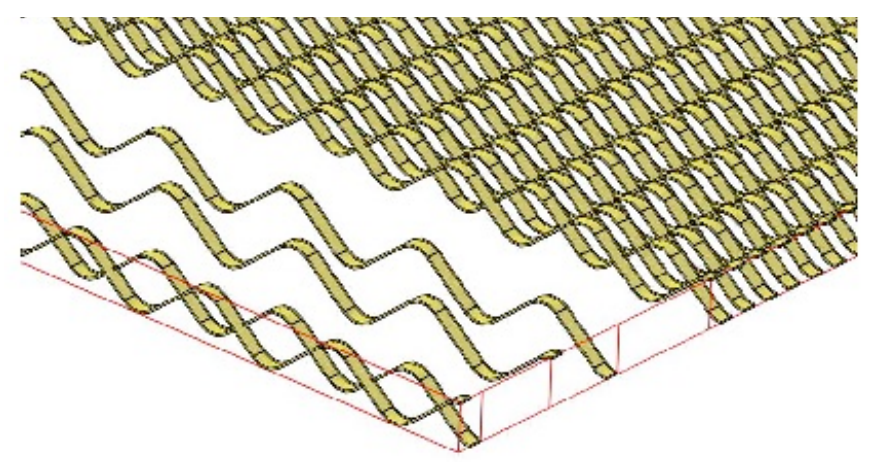

Gambar 1. Susunan lembaran gelombang

Satuan lebaran gelombang itu disusun hingga membentuk inti honeycomb sandwich dengan ukuran panjang $500 \mathrm{~mm}$, lebar $200 \mathrm{~mm}$. Tinggi inti honeycomb sandwich dibuat dua macam, yaitu $12 \mathrm{~mm}$ dan $17 \mathrm{~mm}$. Variasi ketinggian inti honeycomb sandwich ini bertujuan untuk melihat perbedaan kekuatan lentur dan kekakuan dari kedua panel honeycomb sandwich tersebut sebagai akibat dari perbedaan ketingian inti honeycomb. Nomenklatur yang memperlihatkan panjang, lebar dan tinggi inti honeycomb sandwich terdapat pada gambar 2. Inti honeycomb ini selanjutnya akan ditutup bagian atas dan bawahnya dengan lapisan kulit. Inti dan kulit honeycomb dibuat seluruhnya dari serat bambu yang diikat dengan bahan resin polyester.

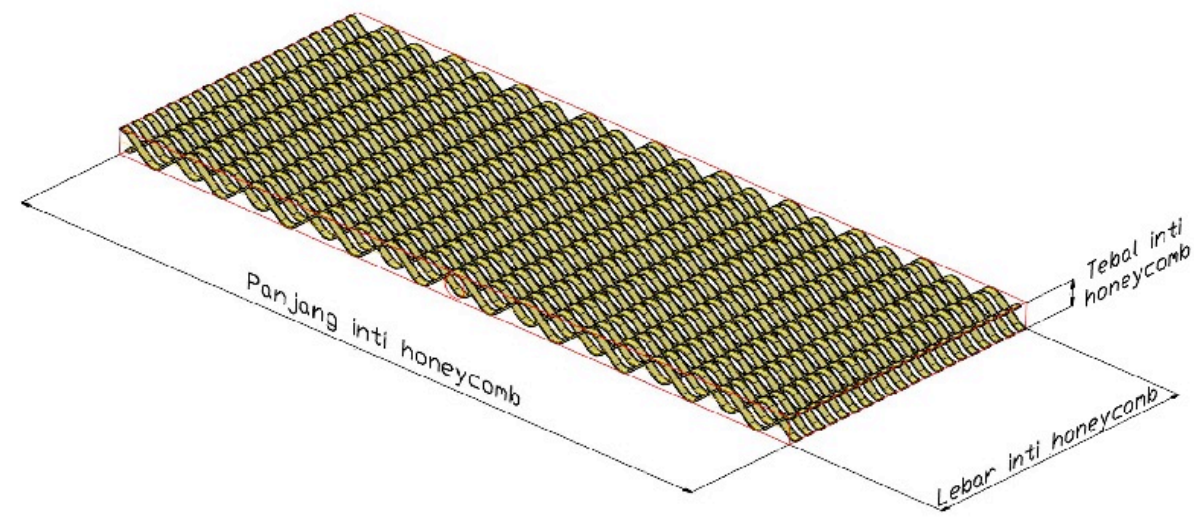

Gambar 2. Nomenklatur inti honeycomb sandwich

Honeycomb sandwich yang dibuat masih berbentuk panel persegi, belum dibentuk menjadi sudu turbin savonius yang berbentuk setengah lingkaran, karena dalam penelitian ini masih dilakukan kajian kekuatan lentur dan kekakuan honeycomb sandwich dalam bentuk panel. Disamping itu, penelitian ini juga masih berada dalam tataran awal, yaitu masih mengkaji teknik pembuatan honeycomb dengan inti berbentuk gelombang sinus dengan cara yang paling mudah. 


\subsection{Pembuatan panel honeycomb sandwich berbahan komposit serat bambu}

Bahan serat yang digunakan dalam pembuatan honeycomb sandwich ini berasal dari bambu jenis Gigantochloa Apus atau sering disebut dengan bambu tali. Bambu ini memiliki kelebihan dalam hal sifatnya yang ulet dan tidak mudah putus pada saat ditekuk. Oleh karena sifatnya ini, bambu tali sering digunakan sebagai bahan baku untuk produk anyaman. Sebagai pengikat serat bambu pada struktur honeycomb sandwich ini digunakan resin Polyester Yukalac 157 BTQN-EX yang umum digunakan pada produk FRP (Fiber-Reinforce Plastic) dengan proses handlay-up dan spray-up molding.

Bambu yang akan dibuat menjadi inti dan kulit honeycomb harus dibentuk menjadi lembaran serat bambu terlebih dahulu dengan cara dibelah-belah dan diserut secara manual. Dari percobaan-percobaan yang dlakukan dalam penelitian ini diketahui bahwa ketebalan serat bambu kira-kira sebesar $0,7 \mathrm{~mm}$ cukup baik untuk dapat dianyam dengan mudah tanpa menimbulkan kerusahan atau patah pada serat bambu tersebut. Serat bambu yang telah memiliki ketebalan yang relatif sama kemudian diolah lebih lanjut untuk mendapatkan serat dengan dua ukuran lebar yang berbeda. Untuk membentuk inti honeycomb sandwich disiapkan serat bambu dengan lebar sebesar $5 \mathrm{~mm}$, sedangkan untuk membentuk kulit honeycomb sandwich disiapkan serat bambu dengan lebar $15 \mathrm{~mm}$.

Inti honeycomb sandwich yang berbentuk gelombang sinus dibuat dengan menggunakan cetakan inti honeycomb yang berbentuk jajaran batang-batang silinder. Jajaran batang silinder dari cetakan itu dipasang pada lubang-lubang yang tersusun pada rangka cetakan bagian sisi yang berbentuk batang. Cetrakan inti honeycombsengaja disusun dari beberapa bagian agar inti honeycomb yang terbuat dari bahan serat bambu dan telah mengeras bersama resin dapat dilepaskan dari cetakan dengan mudah. Pelepasan inti honeycomb yang telah jadi dilakukan dengan cara melepaskan cetakan bagian sisi terlebih dahulu, kemudian dilanjutkan dengan melepaskan silinder-silinder cetakan dari inti honeycomb serat bambu yang telah membentuk gelombang. Susunan jajaran batang silinder yang terpasang pada rangka cetakan bagian sisi terlihat pada gambar 3 .

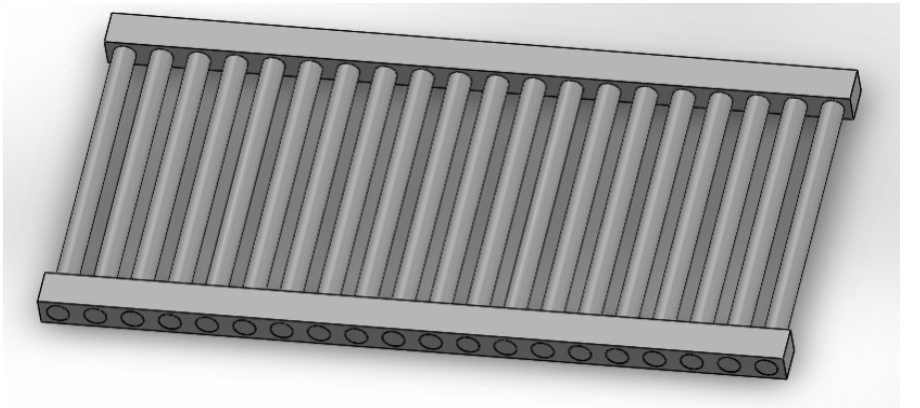

\section{Gambar 3. Cetakan untuk membuat anyaman inti honeycomb dari serat bambu}

Serat-serat bambu dibentuk menjadi inti honeycomb yang berbentuk gelombang dengan cara menganyamkan lembaran serat bambu pada jajaran batang-batang silinder yang sebelumnya telah dilumuri dengan mirror glaze. Penggunaan mirror glaze ini bertujuan agar resin tidak menempel pada cetakan sehingga inti honeycomb yang telah jadi dapat dilepaskan dari cetakan dengan lebih mudah. Serat bambu yang telah dianyamkan pada cetakan inti honeycomb selanjutnya dilumuri dengan resin agar lembaran serat bambu dapat membentuk gelombang serta membentuk ikatan di antara lembaran gelombang serat bambu yang bersebelahan. Pemberian resin pada anyaman bambu terlihat pada gambar 4. Setelah resin mengeras, inti honeycomb dilepaskan dari cetakan kearah samping dengan melepaskan rangka cetakan bagian sisi terlebih dahulu.

Kulit (skin) honeycomb dibuat dengan menggunakan cetakan yang berupa 2 lembar kaca tebal. Penggunaan kaca tebal sebagai cetakan ini bertujuan untuk mendapatkan permukaan kulit honeycomb yang rata. Kulit honeycomb dibuat dengan cara menyusun lembaran-lembaran serat bambu di atas lembaran kaca pertama yang telah dilapisi mirror glaze. Penggunaan mirror glaze ini bertujuan agar resin pengikat tidak menempal pada kaca. Bersamaan dengan penyusunan lembaran-lembaran serat bambu di atas lembaran kaca, diterapkan juga resin pada susunan lembaran serat bambu yang disusun 
tersebut. Penyusunan lembaran serat bambu dilakukan pada arah menyamping, atau berjajar ke arah lebar panel honeycomb. Kulit honeycomb ini dibuat hanya dengan 1 lapis serat bambu, tidak ditumpuk ataupun dianyam silang. Setelah tersusun dengan baik, susunan lembaran serat bambu yang telah diberi resin tersebut selanjutnya ditutup lagi dengan lembaran kaca kedua yang juga telah dilapisi dengan mirror glaze. Kedua lembaran kaca tersebut selanjutnya dijepit dengan klem $\mathrm{C}$ di beberapa titik dan dibiarkan hingga resin mengeras.

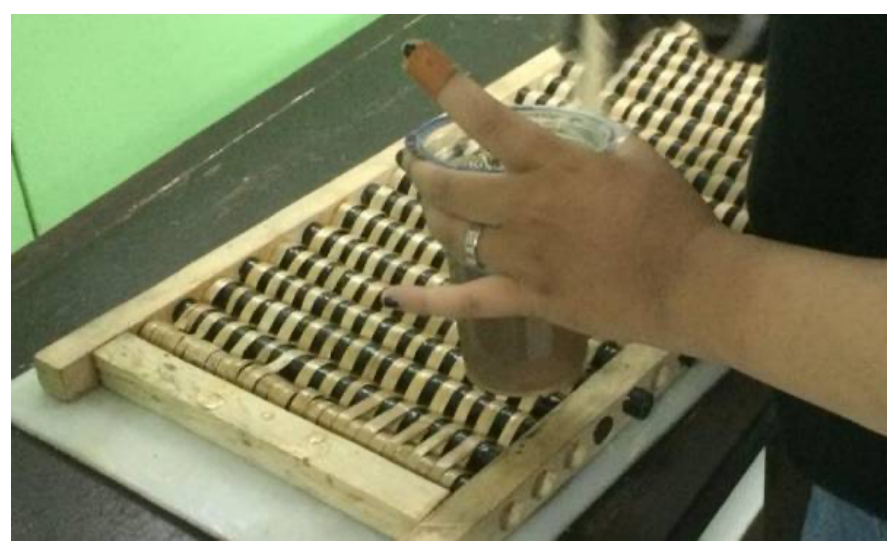

Gambar 4. Pemberian resin pada anyaman serat bambu

Susunan lembaran bergelombang yang telah membentuk inti honeycomb selanjutnya disatukan dengan dua lembar kulit, yang menutup bagian atas dan bagian bawah dari inti honeycomb. Penggabungan kulit atas dan kulit bawah dengan inti honeycomb dilakukan dengan menggunakan resin. Untuk memastikan bahwa sambungan antara kulit dan inti honeycomb terjadi secara sempurna, panel honeycomb yang telah disatukan itu dijepit dengan klem $\mathrm{C}$ di beberapa titik. Proses penggabungan inti honeycomb dengan kulit terlihat pada gambar 5. Bentuk akhir dari panel honeycomb sandwich berbahan serat bambu terlihat pada gambar 6.

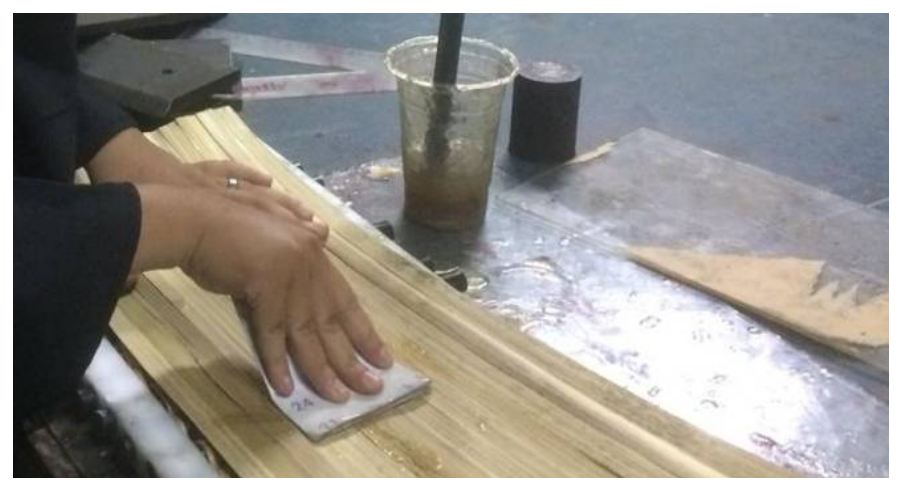

Gambar 5. Pebuatan kulit honeycomb dari serat bambu

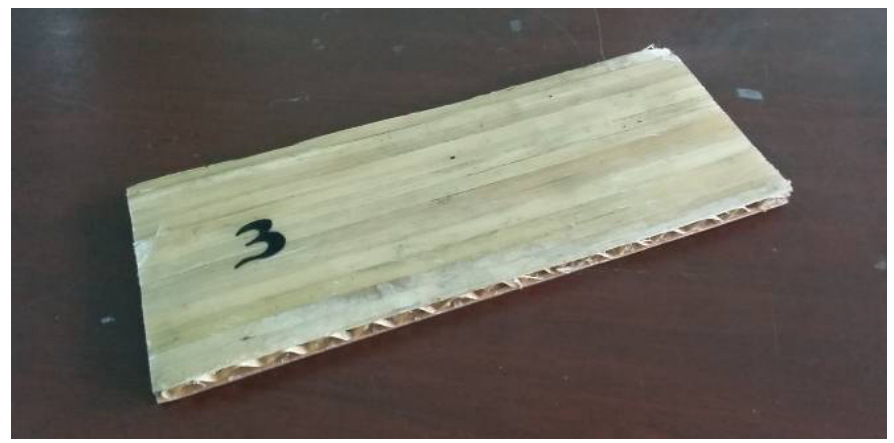

Gambar 6. Honeycomb sandwich berbahan serat bambu yang telah jadi 
Dalam penelitin ini, dibuat specimen panel dengan 2 variasi ketinggian inti honeycomb, yaitu $12 \mathrm{~mm}$ dan $17 \mathrm{~mm}$. Untuk masing-masing ketinggian inti honeycomb dibuat tiga buah specimen panel. Variasi ketinggian inti honeycomb ini dilakukan untuk melihat perbedaan kekuatan lentur dan kekakuan dari kedua ukuran inti honeycomb tersebut.

Pembuatan honeycomb sandwich dengan bahan serat bambu ini cukup sulit dilakukan karena membutuhkan ketelitian dan kesabaran. Terlebih lagi, semua tahapan proses pembuatan, mulai dari tahap persiapan serat bambu, tahap pembuatan inti dan kulit honeycomb sandwich sampai kepada penggabungan inti dan kulit honeycomb dilakukan secara manual. Tantangan terbesar dalam pembuatan honeycomb sandwich berbahan serat bambu ini adalah pada tahapan persiapan serat bambu, yaitu pada saat proses penyerutan serat bambu untuk mendapatkan serat bambu yang relatif tipis dan ketebalan yang seragam pada semua serat bambu. Serat bambu dengan ketebalan yang seragam sangat penting untuk disiapkan karena hal ini akan berdampak kepada keseragaman dimensi dan berat dari panel-panel honeycomb sandwich yang memiliki dimensi yang identik. Keseragaman dimensi dari panel-panel honeycomb sandwich yang identik menjadi penting untuk dicapai agar variabilitas dari kekuatan dan kekakuan dari panel-panel honeycomb sandwich yang identik ini dapat ditekan sekecil mungkin.

\subsection{Pengujian panel honeycomb sandwich}

Spesimen panel Honeycomb sandwich yang dibuat dari bahan komposit serat bambu ini diuji untuk mengetahui karakteristik mekaniknya, yaitu kekuatan lentur (flexural strength) dan kekakuan (stiffness). Spesimen panel honeycomb sandwich ini diuji dengan metoda uji bending, yaitu mengacu kepada standar ASTM C393-00 Standard Test Method for Flexural Properties of Sandwich Constructions [15]. Pengujian bending dilakukan dengan sistem pembebanan satu titik, yaitu tepat di tengah-tengah jarak antara dua tumpuan, sebagaimana yang terlihat pada Gambar 7. Jarak antara tumpuan $\left(\mathrm{L}_{1}\right)$ pada pengujian ini adalah $420 \mathrm{~mm}$. Pembebanan $\left(\mathrm{P}_{1}\right)$ diberikan secara bertahap sampai panel honeycomb sandwich patah

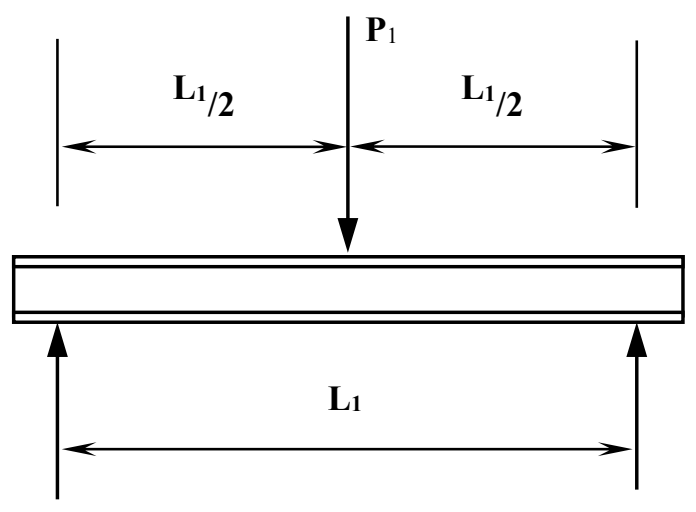

Gambar 7. Pembebanan satu titik [15]

\section{HASIL DAN PEMBAHSAN}

\subsection{Perbandingan berat serat dan berat resin}

Perbandingan berat serat dan berat resin (matriks) pada material komposit penting untuk diukur untuk melihat kecenderungan sifat komposit. Komposisi dari material pembentuk komposit yang lebih besar akan lebih mendominasi sifat dari komposit yang akan terbentuk. Perbandingan berat serat bambu dan berat resin terlihat pada Tabel 1. 
Tabel 1. Berat serat bambu, berat resin, berat total, serta persentase berat serat bambu dan berat resin setiap panel honeycomb Sandwich.

\begin{tabular}{|c|c|c|c|c|c|}
\hline \multirow{2}{*}{$\begin{array}{c}\text { No } \\
\text { Specimen }\end{array}$} & \multirow{2}{*}{$\begin{array}{c}\text { Berat Serat } \\
\text { (gr) }\end{array}$} & \multirow{2}{*}{$\begin{array}{c}\text { Berat Resin } \\
\text { (gr) }\end{array}$} & \multirow{2}{*}{$\begin{array}{c}\text { Berat Panel } \\
\text { (gr) }\end{array}$} & \multicolumn{2}{|c|}{$\begin{array}{c}\text { Perbandingan Serat dan } \\
\text { Resin }\end{array}$} \\
\hline & & & & Serat & Resin \\
\hline \multicolumn{6}{|c|}{ ketinggian inti (core) $12 \mathrm{~mm}$} \\
\hline Specimen 1 & 250 & 449 & 699 & $36 \%$ & $64 \%$ \\
\hline Spesimen 2 & 239 & 550 & 789 & $30 \%$ & $70 \%$ \\
\hline Specimen 3 & 241 & 422 & 663 & $36 \%$ & $64 \%$ \\
\hline \multicolumn{6}{|c|}{ ketinggian inti (core) $17 \mathrm{~mm}$} \\
\hline Specimen 1 & 235 & 444 & 679 & $35 \%$ & $65 \%$ \\
\hline Specimen 2 & 234 & 421 & 655 & $36 \%$ & $64 \%$ \\
\hline Specimen 3 & 241 & 457 & 698 & $35 \%$ & $65 \%$ \\
\hline
\end{tabular}

Perbandingan berat serat bambu dan berat resin yang terlihat pada tabel 1 menunjukkan bahwa komposisi fraksi resin lebih banyak dibandingkan fraksi serat bambu. Hal ini bisa terjadi karena untuk mengikat lembaran-lembaran serat bambu, yaitu pada bagian sambungan serat dengan serat di sebelahnya dibutuhkan resin yang cukup banyak. Resin juga harus menutupi seluruh permukaan serat bambu agar serat tersebut dapat membentuk gelombang. Pada saat pembuatan kulit juga dibutuhkan resin yang cukup banyak agar lembaran-lembaran serat bambu dapat tersambung dengan sempurna dan membentuk lembaran yang rata. Penumpukan resin juga terjadi pada sambungan inti honeycomb yang berbentuk gelombang dengan kulit, yaitu di bagian sudut yang terbentuk pada pertemuan puncak gelombang inti honeycomb dengan kulit.

Berat serat bambu yang dipakai pada semua panel tidak banyak berbeda, walaupun panel yang memiliki tinggi inti honeycomb $17 \mathrm{~mm}$ seharusnya menggunakan serat bambu yang lebih banyak dari panel yang memiliki tinggi inti honeycomb $12 \mathrm{~mm}$. Hal ini bisa terjadi karena serat bambu yang digunakan pada panel dengan tinggi inti honeycomb $12 \mathrm{~mm}$ kemungkinan memiliki ketebalan yang relatif lebih besar daripada serat bambu yang digunakan pada panel dengan tinggi inti honeycomb $17 \mathrm{~mm}$. Ketebalan serat bambu yang tidak seragam sangat mungkin terjadi karena proses persiapan (penyerutan) serat bambu dilakukan secara manual.

\subsection{Massa jenis panel}

Massa jenis panel dihitung dari berat panel dibagi dengan volumenya. Berat spesimen panel ditimbang dengan menggunakan neraca digital yang memiliki kecermatan 0,001gram. Dimensi spesimen panel dan dimensi detail dari inti honeycomb diukur dengan jangka sorong yang memiliki kecermatan $0,05 \mathrm{~mm}$. Dari hasil penimbangan berat dan penghitungan volume spesimen panel honeycomb sandwich diperoleh massa jenis masing-masing panel honeycomb sandwich seperti yang terlihat pada Tabel 2.

Tabel 2. Perhitungan massa jenis panel honeycomb

\begin{tabular}{|c|c|c|c|c|c|c|}
\hline \multirow[t]{2}{*}{ No specimen } & \multirow{2}{*}{$\begin{array}{c}\text { Berat total } \\
\text { panel } \\
\text { (gram) }\end{array}$} & \multicolumn{3}{|c|}{$\begin{array}{c}\text { Dimensi panel } \\
\text { (Panjang xLebar xTebal) }\end{array}$} & \multirow{2}{*}{$\begin{array}{c}\text { Volume } \\
\text { panel } \\
\left(\mathbf{m}^{3}\right)\end{array}$} & \multirow{2}{*}{$\begin{array}{c}\text { Massa jenis } \\
\text { panel } \\
\left(\mathrm{kg} / \mathrm{m}^{3}\right) \\
\end{array}$} \\
\hline & & $\mathrm{P}(\mathrm{mm})$ & $\mathrm{L}(\mathrm{mm})$ & $\mathrm{T}(\mathrm{mm})$ & & \\
\hline \multicolumn{7}{|c|}{ ketinggian inti honeycomb $12 \mathrm{~mm}$} \\
\hline Specimen 1 & 699 & 500 & 200 & 16 & 0.0016 & 437 \\
\hline Specimen 2 & 789 & 500 & 200 & 18 & 0.0018 & 438 \\
\hline Specimen 3 & 663 & 500 & 200 & 16 & 0.0016 & 414 \\
\hline Rata-rata & 717 & & & & 0.0017 & 430 \\
\hline \multicolumn{7}{|c|}{ ketinggian inti honeycomb $17 \mathrm{~mm}$} \\
\hline Specimen 1 & 679 & 500 & 200 & 21 & 0.0021 & 323 \\
\hline Specimen 2 & 655 & 500 & 200 & 21 & 0.0021 & 312 \\
\hline Specimen 3 & 698 & 500 & 200 & 22 & 0.0022 & 317 \\
\hline Rata-rata & 677 & & & & 0.0021 & 318 \\
\hline
\end{tabular}


Panel honeycomb sandwich dengan tinggi inti honeycomb yang sama memiliki berat yang bervariasi, baik untuk honeycomb sandwich dengan tinggi inti $17 \mathrm{~mm}$ dan $12 \mathrm{~mm}$. Padahal seharusnya untuk tinggi inti honeycomb yang sama, berat panel seharusnya relatif sama. Setidaknya ada dua hal yang menjadi penyebab hal tersebut, yaitu tebal serat bambu yang tidak seragam serta banyaknya pemakaian resin yang tidak proporsional untuk setiap panel.

Berat panel honeycomb sandwichyang memiliki tinggi inti17mm tidak banyak berbeda dengan berat panel honeycomb sandwich yang memiliki tinggi inti $12 \mathrm{~mm}$. Dengan perbedaan berat tidak signifikan, tetapi dengan volume yang berbeda, maka massa jenis panel honeycomb sandwich yang memiliki tinggi inti $12 \mathrm{~mm}$ tentunya memiliki massa jenis yang lebih besar.

Kecenderungan berat dan massa jenis panel yang tidak seragam untuk dimensi yang sama menunjukkan bahwa konsistensi pembuatan panel honeycomb sandwich ini masih belum cukup baik. Ketebalan serat bambu yang tidak seragam merupakan salah satu penyebab variabilitas berat dan massa jenis panel. Oleh karena itu, tahap persiapan serat juga menjadi hal yang penting untuk diperhatikan. Ketidakseragaman berat dan massa jenis panel honeycomb sandwich komposit serat bambu juga akan menjadi masalah tersendiri pada saat material komposit ini digunakan untuk membuat sudu turbin angin, yaitu permasalahan dalam hal keseimbangan turbin.

Kesulitan dalam mengolah serat bambu yang panjang untuk dijadikan sebagai penguat (reinforce agent) pada komposit bermatriks polimer kemungkinan menjadi penyebab langkanya penelitian tentang subjek ini. Serat bambu yang pendek dan serbuk bambu lebih banyak digunakan sebagai reinforce agent pada komposit bermatriks polimer karena lebih mudah diolah dan dapat menghasilkan komposit serat bambu dengan dimensi dan massa jenis yang lebih seragam. Produksi komposit serat bambu bermatriks polimer di tingkat industri juga lebih banyak menggunakan serat bambu yang pendek dan serbuk bambu. Hal ini berdampak kepada sulitnya mendapatkan data sifat fisik yang dapat dijadikan sebagai pembanding yang imbang untuk material komposit berpenguat serat bambu dengan struktur honeycomb sandwich yang dibuat dalam penelitian ini.

Data yang tersedia untuk dijadikan pembanding adalah data dari material komposit bermatriks polimer polyester dengan penguat serat bambu yang pendek ataupun serbuk bambu. Komposit ini pun dibuat dalam bentuk padat (solid) dan bukan berupa material dengans struktur honeycomb sandwich. Dari penelitian yang dilakukan oleh Biswas [16] dan Martijanti, et. al. [17] didapatkan data bahwa pada umumnya komposit serat bambu dengan matriks polyester memiliki massa jenis pada kisaran angka $1,15-1,25 \mathrm{gram} / \mathrm{cm}^{3}$ atau $1.150-1.250 \mathrm{~kg} / \mathrm{m}^{3}$. Jika dibandingkan dengan data ini, maka dapat dilihat bahwa spesimen panel dengan struktur honeycomb sandwich yang dihasilkan dalam penelitian ini memiliki massa jenis yang lebih rendah, yaitu 25\% - 27\% lebih kecil daripada material yang sama dengan bentuk padat. Hal ini tentu saja sangat logis karena material dengan struktur honeycomb sandwich memiliki banyak ruang kosong (rongga) yang membuatnya menjadi lebih ringan daripada maerial padat dengan dimensi dan volume total yang sama.

\subsection{Kekuatan lentur dan kekakuan}

Karakteristik mekanik yang ingin didapatkan dari pengujian bending (lentur) terhadap panel honeycomb sandwich berbahan serat bambu ini adalah kekuatan lentur (flexural strength) dan kekakuan (stiffness). Karakteritik mekanik ini didapatkan dari pengolahan data yang diperoleh dari uji bending yang dikombinasikan dengan data dimensi detail dari panel honeycomb sandwich yang telah jadi. Data yang didapatkan dari pengujian bending adalah beban maksimum yang dapat ditahan oleh panel honeycomb sandwich serta besar defleksi maksimum sebelum panel tersebut patah. Data lain yang juga diperoleh dari grafik pengujian bending ini adalah besar gaya maksimum di daerah elastis (daerah proporsional) serta besar defleksi maksimum di daerah elastis. Data dari hasil pengujian bending terlihat pada Tabel 3. 
Marsono, dkk.

Tabel 3. Besar gaya (beban) dan defleksi maksimum pada panel

\begin{tabular}{lllll}
\hline Spesimen & $\begin{array}{c}\text { Gaya (beban) } \\
\text { maksimum }\end{array}$ & $\begin{array}{c}\text { Defleksi } \\
\text { maksimum }\end{array}$ & $\begin{array}{c}\text { Beban maks. } \\
\text { pada daerah } \\
\text { elastis }\end{array}$ & $\begin{array}{c}\text { Defleksi maks. } \\
\text { pada daerah } \\
\text { elastis }\end{array}$ \\
\hline ketinggian inti honeycomb $12 \mathrm{~mm}$ & & & \\
\hline Spesimen 1 & $31.40 \mathrm{~kg}$ & $47 \mathrm{~mm}$ & $27 \mathrm{~kg}$ & $6.5 \mathrm{~mm}$ \\
\hline Spesimen 2 & $48.54 \mathrm{~kg}$ & $52 \mathrm{~mm}$ & $43 \mathrm{~kg}$ & $6,8 \mathrm{~mm}$ \\
\hline Spesimen 3 & $34.37 \mathrm{~kg}$ & $54 \mathrm{~mm}$ & $29 \mathrm{~kg}$ & $6,1 \mathrm{~mm}$ \\
\hline ketinggian inti honeycomb $17 \mathrm{~mm}$ & & & \\
\hline Spesimen 1 & $54.97 \mathrm{~kg}$ & $42 \mathrm{~mm}$ & $51 \mathrm{~kg}$ & $5,4 \mathrm{~mm}$ \\
\hline Spesimen 2 & $58,32 \mathrm{~kg}$ & $35 \mathrm{~mm}$ & $55 \mathrm{~kg}$ & $5,7 \mathrm{~mm}$ \\
\hline Spesimen 3 & $63,41 \mathrm{~kg}$ & $34 \mathrm{~mm}$ & $59 \mathrm{~kg}$ & $5,2 \mathrm{~mm}$ \\
\hline
\end{tabular}

Kekuatan lentur maksimum ( $\left.\sigma_{\text {maks }}\right)$ dari masing-masing panel didapatkan dengan persamaan :

$$
\sigma=\frac{M \times C}{I_{x x}}
$$

Pada perhitungan kekuatan lentur maksimum, momen inersia penampang dari panel honeycomb sandwich tidak sama pada setiap posisi titik potongan penampang. Momen inersia penampang yang digunakan dalam perhitungan kekuatan lentur maksimum adalah momen inersia penampang yang paling kecil, karena di posisi ini akan terjadi tegangan terbesar dan pada posisi ini pula kemungkinan terbesar terjadinya patah.

Kekakuan (K) dari masing-masing panel diperoleh melalui persamaan :

$$
K=\frac{P}{\delta}=\frac{6 E I}{a^{2}(3 L-a)}
$$

Kekakuan panel honeycomb sandwich dihitung pada daerah elastis atau daerah proporsional dari grafik pengujian bending, yaitu daerah dimana kenaikan beban (P) setara dengan penambahan besar defleksi $(\delta)$ pada daerah fungsi linier. Kekuatan lentur maksimum $\left(\sigma_{\max }\right)$ dan kekakuan $(\mathrm{K})$ panel honeycomb sandwich yang didapatkan dari perhitungan ditampilkan pada Tabel 4.

\begin{tabular}{|c|c|c|c|c|c|c|c|}
\hline Spesimen & $\begin{array}{c}\text { Beban } \\
\text { maks. } \\
(\mathrm{kg}) \\
\end{array}$ & $\begin{array}{c}\text { Defleksi } \\
\text { maks. } \\
(\mathrm{mm})\end{array}$ & $\begin{array}{c}\text { Beban maks. } \\
\text { di daerah } \\
\text { elastis } \\
(\mathrm{Kg}) \\
\end{array}$ & $\begin{array}{c}\text { Def. maks. } \\
\text { di daerah } \\
\text { elastis } \\
(\mathrm{mm}) \\
\end{array}$ & $\begin{array}{c}\text { Momen } \\
\text { Inersia } \\
\text { penampang } \\
\text { mm }^{4} \\
\end{array}$ & $\begin{array}{c}\text { kekuatan } \\
\text { lentur } \\
\left(\sigma_{\max }\right) \\
\left(\mathrm{kg} / \mathbf{m m}^{2}\right) \\
\end{array}$ & $\begin{array}{c}\text { Kekakuan } \\
(\mathrm{K}) \\
(\mathrm{kg} / \mathrm{mm})\end{array}$ \\
\hline \multicolumn{8}{|c|}{ Tinggi inti honeycomb $12 \mathrm{~mm}$} \\
\hline Spesimen 1 & 31.40 & 47 & 27,00 & 6.5 & $39.487,50$ & 0,67 & 4,15 \\
\hline Spesimen 2 & 48.54 & 52 & 43.00 & 6,8 & $39.487,50$ & 0,79 & 6,32 \\
\hline Spesimen 3 & 34.37 & 54 & 29,00 & 6,1 & $51.487,50$ & 0,82 & 4,75 \\
\hline Rata-Rata & 38,10 & & & & 43.487.50 & 0,76 & 5,08 \\
\hline \multicolumn{8}{|c|}{ Tinggi inti honeycomb $17 \mathrm{~mm}$} \\
\hline Spesimen 1 & 54.97 & 42 & 51,00 & 5,4 & $72.487,50$ & 0,84 & 9,44 \\
\hline Spesimen 2 & 58,32 & 35 & 55.00 & 5,7 & $72.487,50$ & 0,89 & 9,65 \\
\hline Spesimen 3 & 63,41 & 34 & 59,00 & 5,2 & $80.267,50$ & 0,91 & 11,35 \\
\hline Rata-Rata & 58,90 & & & & $75.080,83$ & $\mathbf{0 , 8 8}$ & 10,15 \\
\hline
\end{tabular}

Tabel 4. Perhitungan kekuatan lentur maksimum dan kekakuan 
Pada tabel 4 terlihat bahwa rata-rata kekuatan lentur dari panel honeycomb sandwich dengan tinggi inti honeycomb $17 \mathrm{~mm}$ tidak jauh berbeda dengan kekuatan lentur dari panel honeycomb sandwich dengan ketinggian inti honeycomb $12 \mathrm{~mm}$. Perbedaannya hanya berada pada kisaran $0,1-0,2 \mathrm{~kg} / \mathrm{mm}^{2}$. Hal ini menunjukkan bahwa perbedaan ketinggian inti honeycomb sebesar $5 \mathrm{~mm}$ tidak memberikan efek yang cukup signuifikan terhadap peningkatan kekuatan lentur pada panel honeycomb sandwich berbahan komposit serat bambu dengan inti berbentuk gelombang.

Seperti halnya keterbatasan data yang tersedia tentang massa jenis, data tentang kekualan lentur dari material komposit polyenster berpenguat serat bambu yang panjang dengan struktur honeycomb sandwich juga sangat sulit didapatkan. Data yang tersedia untuk bisa dijadikan pembanding adalah data dari komposit polyester dengan reinforce agent berupa serat bambu yang pendek dan serbuk bambu dalam bentuk material komposit yang padat (solid). Dari penelitian Biswas [16] dan Martijanti, et. al. [17] didapatkan data bahwa pada umumnya komposit serat bambu dengan matriks polyester pada klaster rendah memiliki kakuatan lentur pada kisaran $30-41 \mathrm{MPa}$ atau $3,06-4,18 \mathrm{~kg} / \mathrm{mm}^{2}$. Jika dibandingkan dengan data ini, maka kekuatan lentur dari material komposit polimer berpenguat serat bambu dengan struktur honeycomb sandwich yang dihasilkan dalam penelitian ini masih belum mencapai kualitas ideal. Angka kekuatan lentur rata-rata yang diperoleh dalam penelitian ini, yaitu $0,76 \mathrm{~kg} / \mathrm{mm}^{2}$ dan 0.88 $\mathrm{kg} / \mathrm{mm}^{2}$, lebih kecil 18\%-29\% daripada material komposit polyester berpenguat serat bambu dalam bentuk padat. Walaupun masih belum mencapai kekuatan lentur yang cukup baik, namun kemungkinan untuk meningkatkan kekuatan lentur dari komposit polyester berpenguat serat bambu yang panjang ini masih sangat terbuka, terutama melalui rekayasa desain geometri dan dimensi dari inti (core) struktur honeycomb sandwich.

Dalam hal kekakuan, Tabel 4 memperlihatkan bahwa angka kekakuan panel honeycomb sandwich dengan ketinggian inti 17mm kira-kira 2 kali lebih besar daripada kekakuan panel honeycomb sandwich dengan ketinggian inti $12 \mathrm{~mm}$. Hal ini menunjukkan bahwa penambahan ketinggian inti honeycomb memberikan efek yang cukup signifikan terhadap peningkatan kekakuan panel honeycomb sandwich. Dengan penambahan ketinggian inti honeycomb sebesar $42 \%$ didapatkan peningkatan kekakuan sebanyak $100 \%$.

Angka kekakuan bukan merupakan parameter sifat mekanik yang umum untuk ditampilkan dalam hasil penelitian karena angka kekakuan bersifat spesifik. Angka kekakuan sangat bergantung dari struktur material atau bentuk penampang dari sebuah batang struktur. Material yang sama dapat saja memiliki kekakuan yang berbeda jika material tersebut memiliki bentuk penampang struktur yang berbeda. Oleh karena itu sangat jarang ditemukan angka kekakuan dalam hasil penelitian yang dipublikasikan.

Defleksi maksimum yang terjadi pada panel honeycomb sandwich sesaat sebelum panel patah mennunjukkan angka yang jauh lebih besar daripada angka defleksi maksimum yang terjadi di daerah elastis. Artinya panel honeycomb sandwichini mengalami defleksi yang besar setelah melampaui daerah elastis sampai mengalami patah. Hal ini menunjukkan bahwa panel honeycomb sandwich berbahan serat bambu dengan inti berbentuk gelombang sinus ini memiliki sifat ulet dan lentur yang cukup tinggi dan tidak mudah pecah. Walaupun rasio komposisi berat serat bambu hanya sebesar 30\% - 36\% dari berat total panel tapi ternyata sifat serat bambu yang lentur dan ulet memberikan kontribusi yang besar terhadap sifat komposit secara keseluruhan.

Untuk mengukur kelayakan penggunaan material dengan struktur honeycomb sandwich berbahan komposit polimer dengan penguat serat bambu yang panjang sebagai bahan uutuk membuat sudu turbin angin Savonius, harus dilakukan pengujian material ini dengan bentuk sudu yang sesungguhnya. 


\section{KESIMPULAN}

Tahapan proses produksi yang telah dilakukan dalam penelitian ini menunjukkan bahwa penggunaan cetakan berupa jajaran silinder cukup efektif untuk membuat inti honeycomb sandwich berbentuk gelombang sinus. Tahap persiapan serat bambu memiliki peran yang penting dalam proses pembuatan honeycomb sandwich berbahan komposit serat bambu, yaitu terutama untuk mendapatkan dimensi dan massa jenis panel yang seragam. Berat panel honeycomb sandwich dengan tinggi inti $12 \mathrm{~mm}$ tidak banyak berbeda dengan berat panel honeycomb sandwich dengan tinggi inti $17 \mathrm{~mm}$. Dengan berat yang sama tapi dengan volume yang berbeda, maka panel honeycomb sandwich dengan tinggi inti honeycomb $12 \mathrm{~mm}$ tentu akan memiliki massa jenis yang lebih besar. Massa jenis terkecil didapatkan pada panel honeycomb sandwich dengan ketinggian inti honeycomb $17 \mathrm{~mm}$, yaitu $312 \mathrm{~kg} / \mathrm{mm}^{3}$. Penelitian ini juga memperlihatkan bahwa perbedaan ketinggian inti honeycomb, yaitu $12 \mathrm{~mm}$ dan $17 \mathrm{~mm}$ tidak memberikan efek yang cukup signifikan terhadap peningkatan kekuatan lentur (flexural strength) pada honeycomb komposit serat bambu dengan inti berbentuk gelombang, namun memberikan efek yang cukup signifikan terhadap peningkatan kekakuan (stiffness) panel. Hasil pengujian terhadap panel honeycomb sandwich berbahan komposit serat bambu dengan bentuk inti gelombang menunjukkan bahwa kekuatan lentur tertinggi didapatkan pada panel dengan ketinggian inti honeycomb $17 \mathrm{~mm}$, yaitu $0,91 \mathrm{~kg} / \mathrm{mm}^{2}$. Kekakuan tertinggi juga dicapai oleh panel yang sama yaitu dengan angka kekakuan 11,35 $\mathrm{kg} / \mathrm{mm}$. Sifat dasar serat bambu yang lentur dan ulet memberikan kontribusi yang besar terhadap sifat dari panel honeycomb sandwich berbahan serat bambu dengan inti berbentuk gelombang sinus, yaitu memiliki sifat lentur dan ulet dan yang cukup tinggi dan tidak mudah pecah.

\section{DAFTAR PUSTAKA}

[1] Jagadish, S., Venkata Sai, T. Venkateswara Rao (2016), "Design and Analysis of Vertical Axis Savonius Wind Turbine", International Journal of Engineering and Technology (IJET), e-ISSN : 0975-4024, p-ISSN : 2319-8613, Vol 8 No 2, pp.1069-1076

[2] Qin, Y., JieXu, Yu Zhang (2009), "Bamboo as a Potential Material Used for Windmill Turbine Blades", Master thesis from Roskilde University, Denmark.

[3] Yang, F., Benhua Fei, Zhengxin Wu, Liang Peng and Yunshui Yu (2014), "Selected Properties of Corrugated Particleboards Made from bamboo Waste (Phyllostachys Edulis) Laminated with Medium-Density Fiberboard Panels", Bio-Resources 9 (11) pp.1085-1096

[4] Kaur, N., S. Saxena, H. Gaur, P. Goyal (2017) "A Review on Bamboo Fiber Composites and its Applications", International Conference on Infocom Technologies and Unmanned Systems (ICTUS'2017), Dec. 18-20, 2017, ADET, Amity University Dubai, UAE, pp.834-849

[5] Roslan, S. A. H., Z. A. Rasid and M. Z. Hassan(2015) "The Natural Fiber Composites Based on Bamboo Fibers: A Review”, ARPN Journal of Engineering and Applied Sciences Vol. 10, No. 15 , pp. 6279-6288.

[6] Tumino, D., Tommaso Ingrassia, Vicenzo Nigrelli, Giuseppe Pitarresi, Vicednzo Urso Miano (2014), "Mechanical Behavior of a Sandwich with Corrugated GRP Core: Numerical Modeling and Experimental Validation", Frattura ed Integrità Strutturale, 30. pp.317-326; DOI: 10.3221/IGF-ESIS.30.39.

[7] Rao, K. K., K. Jayathirtha Rao, A.G. Sarwade, M. Sarath Chandra (2012), "Strength Analysis on Honeycomb Sandwich Panels of different Materials", International Journal of Engineering Research and Applications (IJERA), ISSN: 2248-9622, Vol. 2, Issue 3, pp.365-374

[8] Zaid, N. Z. M., M.R.M. Rejab and N.A.N Mohamed, (2016), "Sandwich Structure Based On Corrugated-Core: A Review" MATEC Web of Conferences 74, 00029 DOI: 10.1051/matecconf/20167400029

[9] Yang, F., Benhua Fei (2012)," The Research on Bamboo-wood Corrugated Sandwich Panel", Proceedings of the $55^{\text {th }}$ International Convention of Society of Wood Science and Technology, Beijing, CHINA 
[10] Roslan, S.A.H., M.Z. Hassan, Z.A. Rasid1, S.A. Zaki, Y. Daud, S. Aziz, S. Sarip and Z. Ismail (2015), "Mechanical Properties of Bamboo Reinforced Epoxy Sandwich Structure Composites", International Journal of Automotive and Mechanical Engineering (IJAME), ISSN: 2229-8649 (Print); ISSN: 2180-1606 (Online) Volume 12, pp. 2882-2892, Universiti Malaysia Pahang, DOI: http://dx.doi.org/10.15282/ijame.12.2015.7.0242

[11] Hassan, M. Z., Siti Amni Roslan, S. M. Sapuan, Zainudin A. Rasid, Ariff Farhan Mohd Nor, Mohd Yusof Md Daud, Rozzeta Dolah and Mohd Zuhri Mohamed Yusoff (2020), "Mercerization Optimization of Bamboo (Bambusa vulgaris) Fiber-Reinforced Epoxy Composite Structures Using a Box-Behnken Design”, Polymers 2020, 12, 1367 ; doi: $10.3390 /$ polym 12061367

[12] Dida, H. P., Sudjito Suparman, Denny Widhiyanuriyawan (2016), "Pemetaan Potensi Energi Angin di Perairan Indonesia Berdasarkan Data Satelit QuikScat dan WindSat", Jurnal Rekayasa Mesin, ISSN: 2477-6041, Vol.7, No.2, pp. 95-101

[13] Ali, M. H. (2013) "Experimental Comparison Study for Savonius Wind Turbine of Two \& Three Blades At Low Wind Speed", International Journal of Modern Engineering Research (IJMER), ISSN: 2249-6645, Vol. 3, Issue 5, pp. 2978-2986.

[14] Badan Pusat Statistik [BPS] Jakarta, (2004). Pusat Inventarisasi dan Statistik Kehutanan \& DirektoratStatistik Pertanian. BPS.

[15] Anonymous (2000), "Standard Test Method for Flexural Properties of Sandwich Constructions", ASTM C393-00, American Society of Testing Material.

[16] Biswas, S., (2012), "Mechanical Properties of Bamboo-Epoxy Composites a Structural Application", Advances in Materials Research, Vol. 1, No. 3, pp. 221-231, http://dx.doi.org/10.12989/aer.2012.1.3.221

[17] Martijanti, Sutarno, Ariadne L. Juwono (2020), "Bamboo Fibers, Fabrication of Bamboo Fiber Reinforced Composites, and Their Mechanical Properties - A Review", International Journal of Emerging Trends in Engineering Research, Volume 8. No. 6, pp. 2346-2359 https://doi.org/10.30534/ijeter/2020/24862020

[18] Mott, R. L. and Joseph A. Untener (2017), Applied Strength of Materials, $6^{\text {th Edition, Boca }}$ Raton, Taylor \& Francis, CRC Press. 